UDC 72.013

\title{
Informational Assessment of Architectural Form Harmony
}

\author{
Negai G.A. \\ Candidate of Architecture, Associate Professor \\ Khmelnytskyi National University, Ukraine \\ Dorofejev O.A. \\ Candidate of Technical Sciences, Associate Professor \\ Khmelnytskyi National University, Ukraine
}

\begin{abstract}
This article considers the problem of objective assessment of the architectural form harmony. The illegality of assessment methods based on the laws of geometric construction of facade compositions on the example of the western Parthenon facade and the use of the "golden section" in the study of proportional structure are grounded. Based on the theory of Eisenko's aesthetic measure and the distinctive theoretical and informational model developed by us, a method of information assessment of the architectural form harmony is proposed. This method is based on the calculation of the amount of visual information contained in the ratios of the elements of the dimensional structure, the identification of information modularity and the establishment of the strength of information connections of the elements relations of the dimensional structure. The assessment of the perceived harmony of the architectural form is carried out in accordance with the principle of the least action and is demonstrated by a specific example.
\end{abstract}

Keywords: architectural form, harmony, proportionality, visual information, information field, field of tolerance.

In today's architectural practice, the assessment of the harmony of design decisions is carried out subjectively, on an intuitive level, both at the design stage and at the stage of approval and adoption of design documentation. However, creative intuition is not always a reliable method of assessing the quality of designed architectural objects, especially the harmony of their architectural form. Therefore, there is a need for an objective assessment of this important characteristic of the architectural environment.

Harmony has always been associated with the "golden section" that began to be "adored" during Leonardo da Vinci's time thanks to his like-minded monk Luca Pacolli. He called the golden ratio "divine proportion." Thus, during the High Renaissance, harmony in architecture began to be identified with the "golden section". And this delusion has been going on for almost 500 years. We will talk about this below. For now, let us remind you that the architecture of Ancient Greece of Pericles' time was considered the most harmonious, 
especially the Parthenon of the Acropolis of Athens, the most authoritative masterpiece of the world architecture. Every researcher who has seen the Parthenon can confirm that it is really excitingly harmonious, it is beautiful. But what makes it so, what is the secret of its harmony?

"Harmonies" in Greek are nails that fasten the wooden elements of ships, making them monolithic, uniting these elements into a single whole. The question arises: what fastened the Parthenon into a coherent architectural composition? What served as "harmonies" for him? And there have always been two answers to this question: the proportions and patterns of geometric construction.

As it has been noted above, harmony has always been identified with the "golden section" - 1: 1,618. But such a ratio of elements of the dimensional structure was not found by the researchers of the Parthenon phenomenon, except for Russian theorists I.V. Zholtovskyi and I.Sh. Shevelyova. The first one resorted to falsification, to "corrections" of the dimensional structure in order to adjust it to the ratio of the "golden section". We will talk about that later. Proponents of the "geometric" concept of the nature of the Parthenon harmony proposed various schemes of construction, which were to convince readers that the secret of the beauty of the Parthenon is solved. One such scheme is given below (Fig. 1). This is a structural analysis of the facade of the Parthenon by D. Hambidge [1].

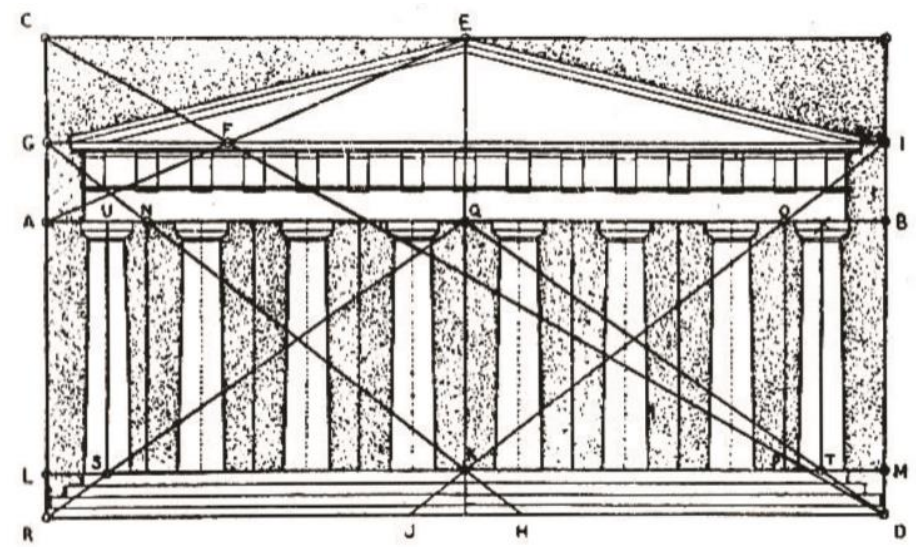

Fig. 1. Scheme of the Parthenon façade's construction (according to D. Hambidge)

D. Hambidge arbitrarily fits so-called "dynamic rectangles" into the Parthenon facade, including the stylobate, despite the fact that it is only a platform on which the temple was built, and therefore its inclusion in the proportional construction is illegal. In addition, the sides of the large rectangle, drawn at the extreme points of the eutentery, are at a distance of 
about one meter from the entablature on each side. Therefore, to put it mildly, such a "correction" of the dimensional structure of the Parthenon facade is not correct. We see the same incorrect geometric construction in Messel's scheme (Fig. 2) on the basis of "circle geometry" as a "standard of proportions" [2].

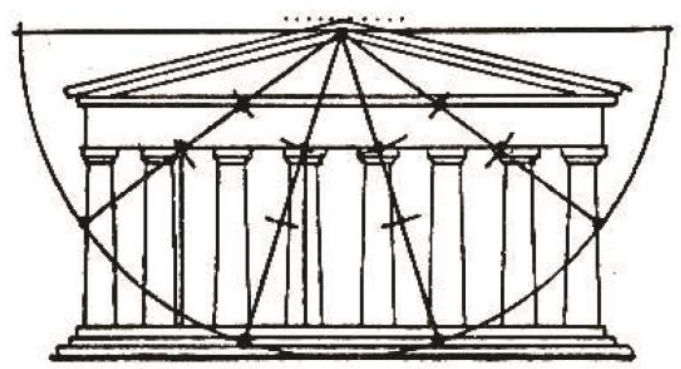

Fig. 2. Structural analysis of the Parthenon facade (according to Messel)

In the ratios needed by I. Zholtovsky to confirm the proportional system of the Parthenon on the basis of "golden section" and "function", he took the height of the pediment without cornice, although the cornice illuminates the pediment field, and the height of the entablature is taken from the top of the cornice to the bottom of capitals. And, again, the ratio of vertical dimensions gable + entablature and colonnade + stylobate, tied to the golden section, is not logical and arbitrary, because stylobate is only a platform for a temple, which is designed to level the rocky surface, and has nothing to do to with the colonnade in the structure. That is, I. Zholtovskyi chose the elements of the dimensional structure arbitrarily so that they fit into the ratio of the golden section. Such a "fit" can not reveal the nature of the Parthenon harmony (Fig. 3).

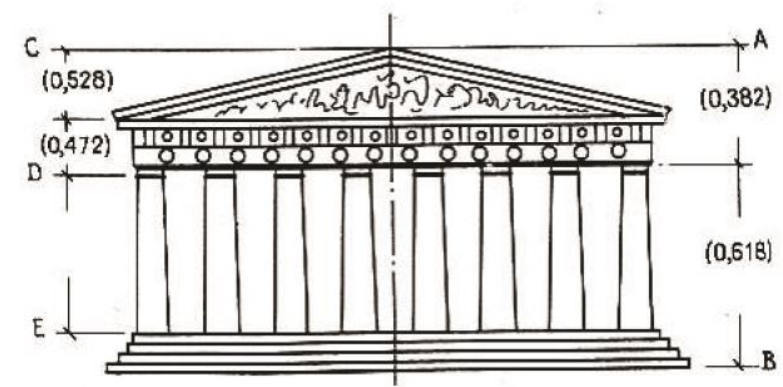

Fig. 3. Analysis of the function of the golden section on the example of the western Parthenon facade 
The most thorough studies of the proportional system of the Parthenon, which could shed light on the nature of the harmony of the Parthenon, were conducted by I. Shevelyov [3]. But the main feature, and at the same time the disadvantage of his study, is that, analyzing the "logic of architectural harmony" of the Parthenon, he took not those elements of dimensional structure that form a visually perceived harmony, but constructive dimensions along the axes of columns. After all, only in the process of visual perception, rather than constructive thinking, we feel the harmony of the architectural form.

The perception and sense of the architectural form harmony occurs through the perception of visual information, the carrier of which is the architectural form. Due to the perception of this information, we perceive and feel the beauty (harmony) of the architectural form.

Since the time of Vitruvius, the concept of harmony has been associated with the concept of proportionality. Harmony was synonymous with beauty. In the Enlightenment, harmony was understood as "unity in diversity." In the early twentieth century this interpretation of harmony was replaced by a clearer formula - "order in complexity."

The author of this concept, Birkhoff, believed that the aesthetic measure is inversely proportional to complexity. Further research and historical practice have shown the complete groundlessness of this understanding of beauty and harmony. Evidence of this is the fact that most of the architectural monuments, built in such complicated styles as Gothic or Baroque, were extremely beautiful. Therefore, Birkhoff's concept was replaced by the opposite concept of Hans Eysenck - beauty is directly proportional to both complexity and order [4].

H. Eysenkck's theory of aesthetic measure was used by us to build a system of informational assessment of the harmony of architectural composition. In 1957 Eysenck proposed a formula for aesthetic measure:

$$
M=O \times C,
$$

where $O$ - orderliness of the object assessed;

$C$ - complexity of the aesthetic assessment of the object.

Eysenkck's aesthetic concept is based on the psychophysiological hypothesis that the feeling of pleasure (aesthetic comfort) is inversely proportional to the mental energy expended on the perception of the object. 
Now, in order to determine the degree of beauty (or harmony, because beauty is the harmony we perceive and feel), it is necessary to determine the physical nature and the degree of complexity and orderliness.

It is not known what criteria Hans Eysenck used to determine complexity and orderliness. His formula of aesthetic measure was empirical, conceptual. However, despite the physical uncertainty of complexity and orderliness, the formula of beauty and harmony is recognized as such which does not contradict the historical practice.

Thus, at the initial stage of formalization of the harmony of the architectural form, one can use the empirical formula of Eysenkck's aesthetic measure.

Complexity, as one of the components of the formula, is quite understandable. It has an informational nature: the more visual information the object of perception contains, the more complex it is and the higher its aesthetic expressiveness, the more harmonious it is. In this case, the object of perception should be as orderly as possible. Orderliness is a quality opposite (inverse) to disorderliness, i.e.

$$
O=\frac{1}{D}
$$

where $D$ - quantified disorderliness.

Now Eysenkck's aesthetic measure will look like this:

$$
M=\frac{C}{D}
$$

The disorderliness of any composition will be determined by the number of relationships between its elements. The more types of relationships, the higher is the disorderliness. The most ordered composition, in accordance with this postulate, will be number one, that is, in case of only one type of relationship.

Thus, the aesthetic measure, visually perceived harmony, depends on the proportional orderliness, because the proportionality is the orderliness of the system of dimensional characteristics of the architectural form in one relationship.

As can be seen from equation (3), harmony is directly proportional to the complexity (C) (informativeness) of the architectural form, or system of relationships, and inversely proportional to the disorderliness $(D)$ of the architectural form. The informativeness of the architectural form can be determined by using our distinctive informational model: 


$$
U=k \cdot \lg \frac{r_{i}}{r_{j}}[5]
$$

where $k$ is the coefficient that takes into account the sensitivity of the visual system to the perception of differences in the elements of the dimensional structure $r_{i}$ and $r_{j}$; with sensitivity $c=\frac{1}{33} \quad k=76,56$.

The amount of visually perceived information contained in relation to two adjacent dimensional characteristics of the architectural form is called the informational step.

Using the above formula (4), we investigate the informational properties of proportionality. All members of any proportional series of quantities are interdependent by dependence:

$$
\frac{r_{i}}{r_{j}}=p^{S}
$$

where $p$ is the basis of a proportional series of quantities, that is, the ratio of two adjacent members of the series;

$s$ - an indicator of the degree that characterizes the relative position of the members of the proportional series, the difference of their serial numbers.

The amount of information contained in one member of the proportional series in relation to any other member of the same series is equal to:

$$
\mathrm{U}=k \cdot \lg \frac{r_{i}}{r_{j}}=k \cdot \lg p^{S}=s k \lg p
$$

where $s=1,2,3 \ldots-$ is an integer of a natural series that depends on the relative position of the elements in this series;

$p$ and $k$-const for any proportional series of values and is its information module $\mu$.

The unit of visual information is the eler-elementary distinction that corresponds to the discriminative sensitivity of the visual system [6]. Elements of the dimensional structure of the architectural form are all the dimensions of architectural divisions that form its compositional system and are the carriers of visually perceptible information, such as width and height of the window opening, column height in the ancient temple, column diameter, entablature height and its elements and so on. 
If in the process of studying the architectural composition, for example, the facade of an ancient temple, the obtained informational steps using the above informational model are multiples of a certain information module, for example, 10 eler ( $\mu=10$ eler $)$, it indicates that the elements of the dimensional structure forming these relations (steps ), one proportional series of values with the base $p=1,35$.

The value of the informational module in relation to the information steps that it connects, characterizes their informational (proportional) unity, and hence the degree of harmony of the architectural form.

Now we can perform an informational analysis of the proportionality of the western facade of the Parthenon, which is recognized as the most harmonious temple of ancient Greece.

To obtain reliable results of the study of the harmony of its facade, at first we will conduct a structural-level differentiation of its elements:

- the level of the whole - the width of the facade (on the architrave), the height of the facade from the upper step of the stylobate to the top of the entablature;

- the level of parts of the whole: the height of the colonnade (from the top step of the stylobate to the bottom of the architrave); the height of the entablature from the upper edge of the abacus to the lower edge of the cornice; the height of the entablature with the pediment; lower intercolumn; the lower diameter of the middle column; the height of the entablature to the modulus;

- level of elements: width of abacus; the distance between the abacus; the upper diameter of the column; upper intercolumn;

- - level of details: width of a triglyph without extreme (not illuminated by the sun) flutes; width of a triglyph with an extreme flute; metope width between triglyphs; width of the metope with the extreme groove of the triglyph.

It is necessary to note that the dimensions of triglyphs and metopes adopted by us pursue the goal of including in the analysis not constructive, but visually perceived elements of the dimensional structure. The same applies to the height of the entablature to the bottom of the cornice, because it casts a deep shadow on the frieze and divides the entablature into two parts, which are visually perceived separately from each other. This is done to clearly delineate the fields of tolerance, because just the lower edge of the cornice divides the upper 
part of the temple into two different fields: a pediment with a sculptural tympanum and a triglyph-metope frieze with an architrave. The lower part, the colonnade, includes two types of tolerance fields: shaded intercolumn cavities and sunlit columns. Stylobate was not included in the calculation because it is actually a leveling platform, which is an extension of the rocky base and has a horizontal structure as opposed to the verticals of columns and intercolumns. In addition, the temple is erected in such a way that the upper plane of the stereobate is at eye level of the person perceiving the view.

The calculation of the amount of visual information contained in the relations of the elements of the dimensional structure of each structural level, informational steps, has been carried out using a distinguishing informational model [4]. Thus, in the numerator of the relation the bigger size has been put to receive positive value of the information. All vertical elements have been increased by $5 \%$, taking into account the revaluation by the visual system of their natural size. Informational steps have been applied to the linear drawing of the facade, forming an informational field. All dimensions have been taken from the monograph by I. Shevelyov [2], who used very accurate measurements of a Greek architect Nicholas Balanos.

Let us follow the informational field of the Parthenon facade from the level of the whole to the level of details on the informational links of correlations:

Integer level:

$$
\begin{aligned}
& \frac{\text { facade width (by architrave) }}{\text { order height }(\text { without stylobate) }} \equiv 25 \text { eler } \\
& \frac{\text { column height }}{\text { lower middle intercolumn }} \equiv 50 \text { eler }
\end{aligned}
$$

As we can see, these correlations have a strong informational connection based on a common informational module $\mu=25$ eler .

The ratio of the level of parts of the whole:

$\frac{\text { height of the upperpart of the temple (from the bottom of the architrave) }}{\text { column height }} \equiv 10$ eler .

The proportionality of the last ratio of the intercolumn is determined by the informational module $\mu=10$ eler - a strong informational connection.

The ratio of the structural level of the elements: 


$$
\begin{aligned}
& \left.\begin{array}{l}
\frac{\text { column height }}{\text { the lower diameter of the column }} \equiv 60 \text { eler; } \\
\frac{\text { upperintercolumn }}{\text { the upperdiameter of the column }} \equiv 20 \text { eler. }
\end{array}\right\} \mu=20 \text { eler ; } \\
& \begin{array}{l}
\frac{\text { abacus width }}{\text { the upperdiameter of the column }} \equiv 10 \text { eler ; } \\
\text { extreme upperintercolumn }
\end{array} \\
& \frac{\text { architraves }+ \text { frieze (to modules) }}{\text { abacus width }} \equiv 10 \text { eler ; } \\
& \frac{\text { architraves }+ \text { frieze (with modules) }}{\text { the interval between the abacuses }} \equiv 10 \text { eler } \text {. }
\end{aligned}
$$

At the level of elements and parts, there are also ratios corresponding to the informational step of 12 eler. They have a strong informational connection with the relationship between the whole and parts of the whole (intercolumn).

Let's compare: $(12+0,5) \times 2=25$ елер and $(12+0,5) \times 4=50$ елер .

The addition of 0.5 eler is legitimate because this value is a subthreshold and is not registered by the human visual system. Informational steps of 20 and 7 eler are informationally connected, having a common informational module of 7 eler: $7 \times 3=21(20+1)$ eler . One eler is the limit for distinguishing and the value of the informational step of 20 eler is not perceived.

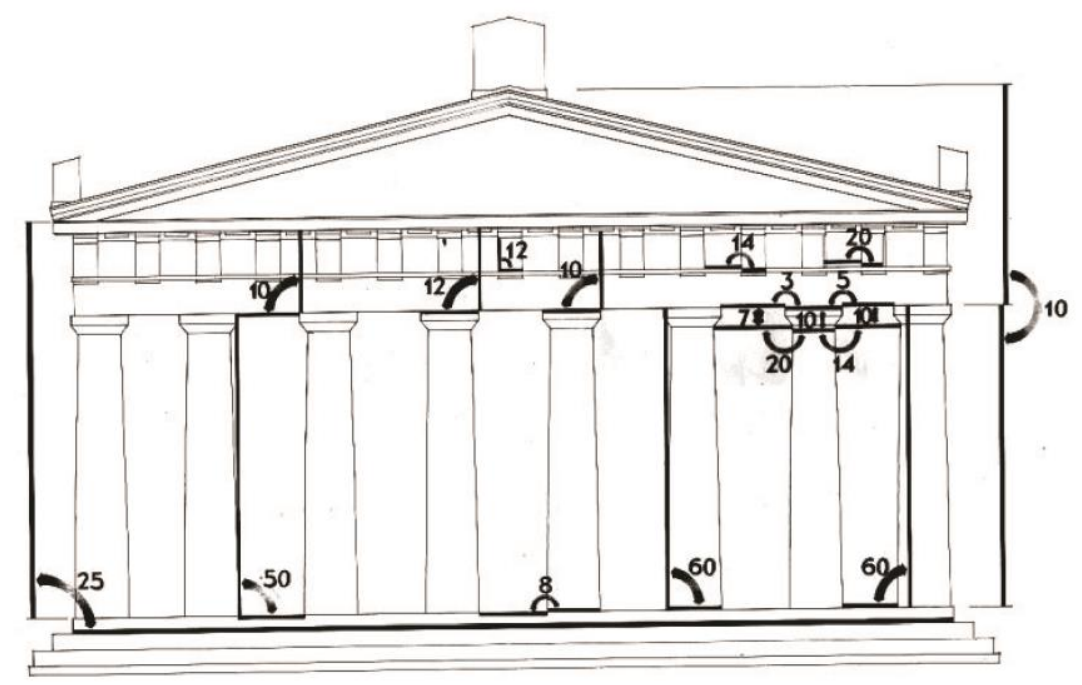

Fig. 4. Information field of the Parthenon facade 
The calculations of informational steps at the levels of the whole and the elements have shown that most of the ratios are related by a common informational module of 10 elers, which indicates that the elements of the dimensional structure belong to one proportional series of values (Fig. 4).

If we substitute in formula (4) $r_{i} / r_{j}=1,618$ - the ratio of the golden section, we obtain 16 elers. As you can see, there is no such informational step in the informational field of the Parthenon facade. This means that the harmony of the western façade of the Parthenon has nothing to do with the golden ratio.

What can explain such an obvious informational unity of the relations of the elements of the dimensional structure of the Parthenon? How did the chief architect of the Parthenon, Iktin, achieve high proportions? It is not known whether he used only fantastic intuition and a sense of harmony, or whether he used a certain mathematical apparatus. One can only assume that in the Pythagorean era, when the Parthenon was created, its harmony was the result of the Pythagorean quantitative concept of harmony. It is most likely that Iktin used the method of elevation and extraction of square and cubic roots. Alberti drew attention to this: "... for the limitations of the parties there are some relations that cannot be determined by numbers, but are drawn from the roots and degrees" [7 books. 9, ch. 6, p. 323] (highlighted by us).

If we elevate to the $2 \mathrm{nd}, 3 \mathrm{rd}, 4$ th and 5th degree 1.35 ( $\equiv 10$ eler) and substitute into formula (4), we get: 20, 30, 40, 50 eler. Exactly these informational steps we see on the informational field of the Parthenon facade.

After the informational research, a natural question arises - is it possible to determine the absolute assessment of the harmony of two alternative objects to choose the best?

We think it is possible. But not by considering that these objects are built on the basis of a golden section, or some other "authoritative" proportion. As shown above on the example of the Parthenon, harmony is not always associated with the golden ratio. And if so, then what does the feeling of harmony of objects of perception depend on?

It should be reminded that the feeling of harmony of the architectural form is a purely informational phenomenon associated with the perception of visual information. The harmony of the architectural form can be quantified if we consider it as a sensory 
phenomenon in terms of the general scientific essence of perception. It takes into consideration the fact that any living system to ensure its viability seeks for consuming the maximum amount of information from the external environment at the minimum cost of already accumulated information to absorb the incoming. This is quite logical, because development is the accumulation of information, and if the system spends more than it receives, it will not develop, it will degrade. Thus, this progressive meaning of informational processes in living nature reflects the principle of the least action.

If we consider the information coming to our visual system as a result of the interaction of this information with human informational memory, then the rationality of this interaction will be judged by how many firmware of our memory is used in the process of perception and how much information fell on one firmware.

As early as 1912, D. Bancroft gave the following interpretation of the principle of the least action for biological systems: "Changes that affect the system (biological), such that they seek to minimize the perturbation of the external order" [7, p. 12]. In other words, informational processes take place in the biological system in such a way as to organize the information of the external world as much as possible in order to perform a minimum number of actions on its perception. This is the principle of the least effect of visual perception.

Since the information, according to our interpretation of A. Kolmogorov, is the "length of the perception algorithm", and informational modules are separate operations that connect adjacent informational steps, the effectiveness of perception will be determined by the amount of information per operation. This value will reflect the magnitude of the visual system and the informational order of the architectural form, that is, its proportionality (harmony).

The size of the informational module in relation to the informational steps that it connects, characterizes their informational unity. If we take the maximum unity indicator for 1 , then it can be achieved only if the informational steps are the same, i.e., their information module will be equal to the informational steps, i.e., $U_{i}=U_{j}=\mu$. In this case, the indicator of informational unity (strength of harmony) is determined by the formula:

$$
P_{h}=\frac{2 \mu}{U_{i}+U_{j}} .
$$


The same formula will determine the indicator of the strength of proportionality (harmony) of any pairwise adjacent informational steps of the architectural form. The number of informational modules contained in two adjacent informational steps is their modular capacity:

$$
E_{c a p}=\frac{U_{i}+U_{j}}{\mu_{i j}} .
$$

The modular capacity of the composition containing $m$ pairs of informational steps will be equal to:

$$
E_{c o m}=\sum_{2}^{m} \frac{U_{i}+U_{j}}{\mu_{i j}} .
$$

The index of harmony (measure of harmony) of the composition, containing $m$ pairs of information steps, will be equal to:

$$
M_{\text {har }}=\frac{\sum_{2}^{m} u_{i}+u_{j}}{E_{\text {com }}} .
$$

The indicator of harmony $M_{h a r}$ characterizes the strength of the informational unity of the relations of the dimensional structure of the architectural composition. The stronger the information connection of neighboring informational steps, the fewer informational modules are embedded in their total information. The more information per information module, the higher is the rate of harmony.

If we accept the position of A. Kolmogorov that information is a manifestation of complexity, then in formula (10) in the numerator we get the complexity. The informational unity of the architectural form is a consequence of its proportionality. Therefore, the total modular capacity $E_{c o m}$ in the denominator will characterize the degree of disorderliness of the architectural form.

Thus, the indicator of harmony is a function of the complexity and orderliness of the architectural form and can be considered as an informational interpretation of Eysenkck's aesthetic measure.

We are sure that any architect would like to check his subjective assessment with a quantitative one or quantitative (informational) assessment with a sensory one. To carry out such a check, we give an example of two compositions in the form of two rectangles with the 
same type of divisions, but with different ratios of the elements of the dimensional structure (Fig. 5).

They correspond to the informational fields below. In the center of each component and near the arrows are the informational steps of the relations of the elements of the dimensional structure, which can be checked using the formula (4). It should be mentioned that the logarithm of $\lg$ is decimal. We are showing the final result of the calculation: composition $A$ - an indicator of harmony $M_{\text {har }}^{A}=2$; composition $B$ - an indicator of harmony $M_{\text {har }}^{B}=3$.

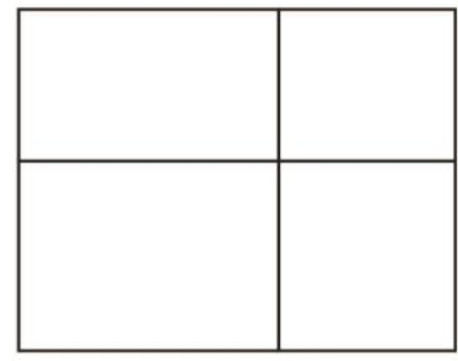

A

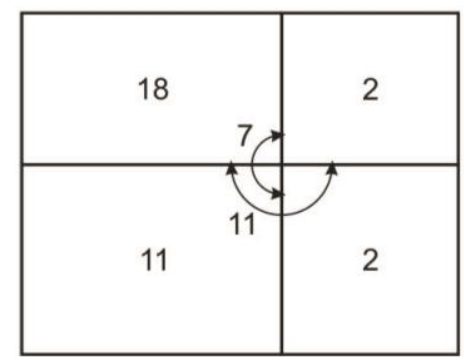

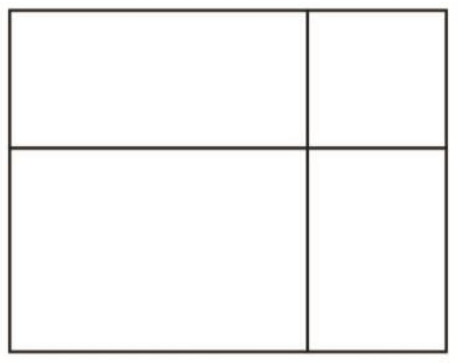

$B$

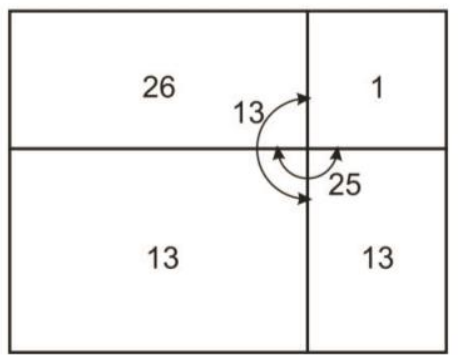

Fig. 5. Dimensional structure and informational field of planar compositions $A$ and $B$.

As you can see, composition B has a higher rate of harmony, despite the very small informational step of 1 eler in the upper right element of the composition. The high rate of harmony provided a strong informational connection of other parts of the composition based on the informational module of 13 (thirteen) eler. This figure is confirmed sensually. Most of the participants of the expert survey, who were asked to answer the question after presenting these two compositions: "Which composition in terms of comfort of perception do you prefer?" - responded in favor of the composition $B$.

Conclusion. In our research the informational method of the analysis of proportionality of dimensional structure of an architectural form and its demonstration on an 
example of information research of the Parthenon western facade has been offered. The results of this study are some unexpected discoveries:

- the visually perceived structure does not contain a "golden section" in relation to the visually perceived structure;

- the main unifying ratio of the dimensional structure is 1.35 , which corresponds to the informational step of 10 elers; it is the main "scraper" of the relations of dimensional structure, which provides the facade with the famous harmony;

- an extremely important role in the formation of the harmony of the Parthenon facade was played by the ratio of the overall dimensions of the facade (the level of the whole) and the intercolumn (the level of parts of the whole) - informational module of 25 eler (!);

- the proposed method of informational assessment of the harmony of the architectural form can be automated and used in computer design of architectural objects in case of software development.

\section{References}

1. Petrovich D. Theorists of proportions / D. Petrovich. - M. : Strojizdat, 1979. $193 \mathrm{p}$.

2. Messel E. Proportions in Antiquity and the Middle Ages / E. Messel. - M. : Kniga po Trebovaniyu, 2014. $-260 \mathrm{p}$.

3. Shevelev I. The Logic of Architectural Harmony / I. Shevelev. - M. : Strojizdat, 1973. $-188 \mathrm{p}$.

4. Mak-Uini G. Overview of Aesthetic Measurements // Semantics and Artmetry. M. : «Mir», 1972. - P. 35-49.

5. Negaj G. A. Distinctive Informational and Theoretical Model of the Dimensional Structure of the Facade Composition // Organization, methods and design technology. Abstract information TsINIS. Ser. XIII.- M. , 1976. - Vol. 1. - P. 17-21.

6. Negaj G. A. Informational Theory of Proportionality in Architecture // The state of modern building science 2006 / IV International scientific and practical Internet conference. Collection of scientific papers. - Poltava: 2006. - P. 225.

7. Alberti L. Ten Books on Architecture (in two volumes) / L. Alberti. - M. : Publishing House of the All-Union Academy of Architecture, 1935. - 392 (I), 792 (II) p.

\section{Translation of the References to the Author's Language}


1. Петрович Д. Теоретики пропорций / Д. Петрович. - М. : Стройиздат, 1979. $193 \mathrm{c}$.

2. Мессель Э. Пропорции в античности и в средние века / Є. Мессель. - М. : Книга по Требованию, 2014. - 260 с.

3. Шевелев И. Логика архитектурной гармонии / И. Шевелев. - M. : Стройиздат, 1973. - 188 с.

4. Мак-Уини Г. Обзор по эстетическим измерениям // Семантика и искусствометрия. - М. : «Мир», 1972. - С. 35-49.

5. Негай Г.А. Различительная теоретико-информационная модель размерной структуры фасадной композиции // Организация, методы и технология проектирования. Реферативная информация ЦИНИС. Серия XIII. - М. , 1976. - Вып. 1. - C. 17-21.

6. Негай Г.А. Информационная теория соразмерности в архитектуре // Состояние современной строительной науки 2006 / IV Международная научнопрактическая интернет-конференция. Сборник научных трудов. - Полтава: 2006. C. 225 .

7. Альберти Л. Десять книг о зодчестве (в двух томах) / Л. Альберти. - М. : Изд-во Всесоюзной академии архитектуры, 1935. - 392 (I), 792 (II) с. 